\title{
Commentary: One port in a storm?
}

\author{
Stephen R. Hazelrigg, MD
}

It is always useful to see and read how experienced surgeons handle complicated and infrequently performed operations. When preparing for an operation such as sleeve resection it is common for surgeons to call upon the literature for review. The article by Gonzalez-Rivas and colleagues ${ }^{1}$ can certainly be helpful in this regard.

It is interesting how we have evolved with regard to minimally invasive lung surgeries. The move from a predominantly open thoracotomy to thoracoscopic approaches for lobectomy was not without some resistance. Many appropriate questions about safety and adequacy of the oncologic results were asked. Advantages with regard to pain and hence other postoperative pulmonary complications seemed almost assured. Gradually, data were published that showed significant advantages for video-assisted techniques with regard to pain and also showed equivalent oncologic outcomes, to support video-assisted thoracoscopic surgery. The movement or advance from an open thoracotomy to multiport thoracoscopic surgery was clearly a significant move forward. Now the movement suggested is from a multiport thoracoscopic approach to a uniport approach. I suggest that the advantages of uniportal surgeries are not yet clear and it is doubtful that there will be as dramatic of an improvement as was seen in going from open to thoracoscopic surgeries and I believe that the bar for safety should be set very high.

As the authors acknowledge, they are describing advanced procedures. Many thoracic surgeons infrequently perform sleeve resections and therefore it may be difficult for the average surgeon to get through the learning curve

\footnotetext{
From the Division of Cardiothoracic Surgery, Southern Illinois University Medicine, Springfield, Ill.

Disclosures: The author reported no conflicts of interest.

The Journal policy requires editors and reviewers to disclose conflicts of interest and to decline handling or reviewing manuscripts for which they may have a conflict of interest. The editors and reviewers of this article have no conflicts of interest.

Received for publication March 10, 2020; revisions received March 10, 2020; accepted for publication March 13, 2020; available ahead of print April 1, 2020.

Address for reprints: Stephen R. Hazelrigg, MD, Division of Cardiothoracic Surgery, SIU Medicine, 701 N First St, Suite D252, Springfield, IL 62702 (E-mail: shazelrigg@siumed.edu).

JTCVS Techniques 2020;2:167

2666-2507

Copyright (C) 2020 The Authors. Published by Elsevier Inc. on behalf of The American Association for Thoracic Surgery. This is an open access article under the CC BY-NCND license (http://creativecommons.org/licenses/by-nc-nd/4.0/).

https://doi.org/10.1016/j.xjtc.2020.03.006
}

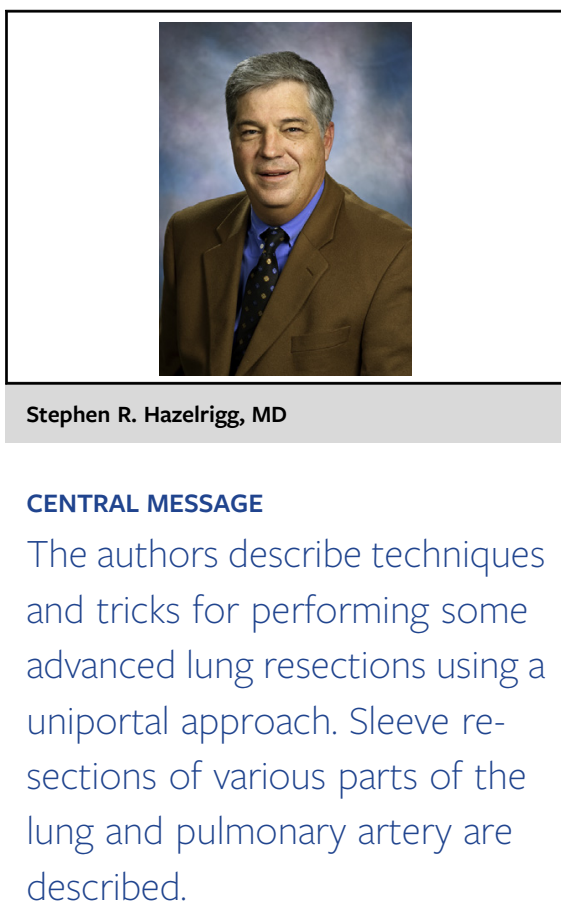

that is required to move to a uniportal approach. Clearly, the advanced procedures described in this article can be done safely by some surgeons; however, I suggest extreme caution for most. The advantages of uniportal over multiportal thoracoscopic surgery remain unclear and are likely not dramatic. Given this fact, I stress the safest approach in each individual surgeons hands. Adding another port or 2 is unlikely to be seen as failure or as a sign of weakness. Any port in a storm - as the saying goes-so don't be embarrassed to use a couple of extra ports if that adds to the safety of performing the surgery.

During the past 30 years we have seen a great deal of innovation in thoracic surgery. Time will tell if uniportal sleeve resections prove to be another advance.

\section{Reference}

1. Gonzalez-Rivas D, Garcia A, Chen C, Yang Y, Zhu Y, Jiang G. Technical aspects of uniportal video-assisted thoracoscopic sleeve resections: where are the limits? J Thorac Cardiovasc Surg Tech. 2020;2:160-4. 